doi:10.1017/S1041610221000879

\section{People with young-onset dementia and their families experience distinctive impacts of the COVID-19 pandemic and associated restrictions}

Evidence is emerging to describe the impacts of the COVID-19 pandemic and associated restrictions for older people with dementia, who are at high risk of contracting the virus (Hariyanto et al., 2021) and experience rapid worsening of behavioral and psychological symptoms (Cagnin et al., 2020). People with dementia report reduced psychological wellbeing and increased anxiety associated with COVID-related social service closures (Giebel et al., 2021). Family members of people with dementia have reported increased levels of stress and caregiving load during lockdown measures (Cohen et al., 2020), especially where they reported anxiety about the virus itself (Savla et al., 2020) and where they withdrew from support services for the safety of the person with dementia (Giebel et al., 2020).

Research has yet to specifically examine the COVID-related experiences of those with young-onset dementia (YOD) (with symptom onset prior to 65 years), which represents $8 \%$ of all dementias and 5 million cases in the US, 42,000 in the UK, and 27,000 in Australia (Brown et al., 2017). People with YOD report higher rates of distress and carer burden than their older counterparts, partly related to their higher financial, familial, and occupational responsibilities (Cations et al., 2017; Ryan et al., 2021). In Australia, YOD care is funded and delivered in the disability system (rather than aged care). People with YOD and their families may therefore have distinct experiences with COVID-19 and support needs that require a tailored response.

We invited Australians living with YOD or providing informal care to a person with YOD to complete a cross-sectional, mixed-methods survey about how the COVID-19 pandemic and associated restrictions have impacted their care. Participants were diagnosed with YOD or currently providing informal support to a person with YOD and were re-contacted after participating in an earlier survey study (Cations et al., 2021). Surveys were completed in May-June 2020, 3 months after the first recorded Australian case of COVID-19. Strict lockdown restrictions, including the closure of non-essential services, were gradually being eased across the country (Lupton, 2020).
The survey was granted ethical approval by the Flinders University Social and Behavioural Research Ethics Committee (Project 8331).

Participants were 12 people living with YOD and 41 unpaid carers of a person with YOD. Most respondents (or those they care for) were diagnosed with Alzheimer's disease $(n=29)$ or frontotemporal dementia $(n=11)$, with median onset age of 56 years. Twenty-five percent of informal carers provided care for a person living in residential care. Quantitative data were summarised using descriptive statistics (e.g. means and percentages), and openended qualitative responses were transcribed verbatim and examined for themes using a thematic analysis approach with open coding to generate themes (Cavanagh, 1997). Particular attention was paid to data indicating unique impacts for young people with dementia (i.e. those that may be less relevant for older people with dementia or those without dementia). Illustrative quotations are included here as representative examples of the themes identified.

Most participants reported that the pandemic negatively impacted on their care in some way (Table 1). Many reported similar barriers to service access as have been reported by older people with dementia (Giebel et al., 2021), including service shutdowns and restrictions on visitation to residential care. However responses were marked by a sense of urgency about access to physical and social activity for maintaining otherwise good physical health. As one survey respondent living with YOD noted, "My body is healthy and regular social interaction helps to regulate my symptoms, so lack of contact is making things terrible for me." Many noted difficulties managing the behavioral and psychological responses to the stress, isolation, and boredom caused by COVID-19 restrictions, especially for those with frontotemporal dementias.

Carers noted that their already high caring responsibilities for the person with YOD, young children, and sometimes also aging parents were each simultaneously increased by the pandemic. Carers with young children affected by school closures were faced with what one described as "an excruciating caring load" with little opportunity for respite. Residual impacts of working from home, losing work, and/or interrupting work to suit strict facility visitation times were noted to reduce tolerance and empathy such that the quality of care was negatively affected. 
Table 1. Summary of survey responses with illustrative quotations

\begin{tabular}{|c|c|c|}
\hline STATEMENT & $\begin{array}{l}N(\%) \\
\text { ENDORSED }\end{array}$ & EXAMPLE RESPONSE \\
\hline $\begin{array}{l}\text { I/We have been unable to access one or more } \\
\text { support services }\end{array}$ & $33(80.5)$ & $\begin{array}{l}\text { "Even when visitors are allowed, most support workers are } \\
\text { mums and can't work when their kids are at home." }\end{array}$ \\
\hline $\begin{array}{l}\text { I/We have been unable to access one or more } \\
\text { health service }\end{array}$ & $16(40.0)$ & $\begin{array}{l}\text { "Because of the lockdown [the nurse] was unable to keep an } \\
\text { eye on her oedema - now she has very red, painful and } \\
\text { swollen legs." }\end{array}$ \\
\hline $\begin{array}{l}\text { I/We have felt concerned about our risk for } \\
\text { contracting COVID-19 from support or } \\
\text { healthcare workers }\end{array}$ & $18(43.9)$ & $\begin{array}{l}\text { "Support workers did not seem to be using any PPE. Not all } \\
\text { support providers had a plan or policy for handling } \\
\text { COVID-19 contact." }\end{array}$ \\
\hline $\begin{array}{l}\text { I/We have been satisfied with measures taken } \\
\text { by support or healthcare workers to reduce } \\
\text { the risk of transmission }\end{array}$ & $35(85.4)$ & $\begin{array}{l}\text { "There has been a quick response in development and } \\
\text { communication of policies and practices at the group home." }\end{array}$ \\
\hline $\begin{array}{l}\text { I/We have cancelled or reduced use of services } \\
\text { because of concerns about contracting } \\
\text { COVID-19 }\end{array}$ & $15(36.6)$ & $\begin{array}{l}\text { "We cancelled our Saturday service largely because the worker } \\
\text { said she was still going to a lot of other homes..." }\end{array}$ \\
\hline $\begin{array}{l}\text { Managing my/the person I support's dementia } \\
\text { symptoms has been more difficult because } \\
\text { of the COVID-19 pandemic }\end{array}$ & $36(87.8)$ & $\begin{array}{l}\text { "[The person with YOD I support] relies heavily on } \\
\text { predictable routine, and they depend on the regular presence } \\
\text { of close family members but that has suddenly been } \\
\text { removed. They don't really understand and so become easily } \\
\text { distressed." } \\
\text { "I am working from home, trying to home school my kids, and } \\
\text { trying to keep my husband engaged and busy. I am } \\
\text { drowning." (Care partner survey respondent) } \\
\text { "Without me there a few times a week, it takes forever to get } \\
\text { anything done." }\end{array}$ \\
\hline
\end{tabular}

COVID-19: Coronavirus 2019; PPE: personal protective equipment; YOD: young-onset dementia.

About $15 \%$ of participants reported dissatisfaction with disability support workers' insufficient use of personal protective equipment (PPE). One responded noted that "the carers go from house to house and don't wear protective gear or use hand sanitiser." One care partner respondent noted concerns that the disability workforce providing in-home support may lack health expertise: "There are no nurses, and I don't know how much training in infection control these people get."

This small study provides early insight into the impacts of the COVID-19 pandemic for people with YOD and their families. Our sample reported similar experiences and concerns with care related to the pandemic and associated restrictions as those reported by older people with dementia and their families in international studies, including social isolation, boredom, and loneliness (Hanna et al., 2021), an associated increase in challenging behavioral responses (Cagnin et al., 2020), and anxiety both about contracting the virus and the ongoing impacts of restricted access to supports (Hariyanto et al., 2021).

International studies have demonstrated that retaining their often good physical health is a priority for people with YOD (Bakker et al., 2010), and in this context the loss of access to allied health and other services has been devastating. For care partners, service restrictions were often paired with school closures and work stressors that combined to further amplify their already high caring load (Lockeridge and Simpson, 2013). Dissatisfaction with PPE use and other risk reduction strategies among the dementia care workforce has been reported among family carers of people with dementia (Giebel et al., 2020). These concerns were echoed here and, on a local level, continue to raise questions about the ability of the disability workforce in Australia to adequately limit the risk of COVID-19 transmission (Kavanagh et al., 2020). Disability and healthcare services are poorly integrated in Australia, and disability professionals often do not have health training. Outbreaks of COVID-19 in disability settings in the months following our study support the suggestion that additional resources are required to prevent further harm (Kavanagh et al., 2020).

\section{Conflicts of interest}

MC has been employed in the past 5 years to assist with data collection for Alzheimer's disease drug trials funded by Janssen and Merck. All other authors declare no conflicts of interest. 


\section{Description of authors' roles}

MC obtained funding for this study, analyzed the data, and drafted and edited the manuscript. SD conducted recruitment and data collection. KL, AW, and BD provided oversight for the study and assisted with manuscript editing.

\section{Acknowledgments}

This research was funded by a Dementia Australia Research Foundation project grant.

\section{References}

Bakker, C. et al. (2010). Needs in early onset dementia: a qualitative case from the NeedYD study. American fournal of Alzheimer's Disease Eo Other Dementiasr, 25, 634-640.

Brown, L., Hansnata, E. and La, H. A. (2017). Economic Cost of Dementia in Australia 2016-2056. Canberra, Australia: Alzheimer's Australia.

Cagnin, A. et al. (2020). Behavioral and psychological effects of Coronavirus Disease-19 quarantine in patients with dementia. Frontiers in Psychiatry, 11. https://doi.org/10 .3389/fpsyt.2020.578015

Cations, M., Day, S., Laver, K., Withall, A. and Draper, B. (2021). Post-diagnosis young onset dementia care in the National Disability Insurance Scheme. Australian and New Zealand fournal of Psychiatry, In Press.

Cations, M. et al. (2017). Why aren't people with young onset dementia and their supporters using formal services? Results from the INSPIRED study. PLoS One, 12, e0180935. https://doi.org/10.1371/journal.pone.0180935

Cavanagh, S., 1997. Content analysis: concepts, methods and applications. Nursing Research, 4, 5-16.

Cohen, G., Russo, M. J., Campos, J. A. and Allegri, R. F. (2020). Living with dementia: increased level of caregiver stress in times of COVID-19. International Psychogeriatrics, 32, 1377-1381. https://doi.org/10.1017/ S1041610220001593

Giebel, C. et al. (2020). Decision-making for receiving paid home care for dementia in the time of COVID-19: a qualitative study. BMC Geriatrics, 20, 333. https://doi.org/ 10.1186/s12877-020-01719-0

Giebel, C. et al. (2021). A UK survey of COVID-19 related social support closures and their effects on older people, people with dementia, and carers. International fournal of Geriatric Psychiatry, 36, 393-402.

Hanna, K. et al. (2021). Emotional and mental wellbeing following COVID-19 public health measures on people living with dementia and carers. Fournal of Geriatric Psychiatry and Neurology, 0891988721996816. https://doi .org/10.1177/0891988721996816

Hariyanto, T. I., Putri, C., Arisa, J., Situmeang, R. F. V. and Kurniawan, A. (2021). Dementia and outcomes from coronavirus disease 2019 (COVID-19) pneumonia: a systematic review and meta-analysis. Archives of Gerontology and Geriatrics, 93, 104299. https://doi.org/10.1016/j .archger.2020.104299

Kavanagh, A. et al. (2020). Improving health care for disabled people in COVID-19 and beyond: lessons from Australia and England. Disability and Health fournal, 14, 101050.

Lockeridge, S. and Simpson, J. (2013) The experience of caring for a partner with young onset dementia: how younger carers cope. Dementia, 12, 635-651.

Lupton, D. (2020) Timeline of COVID-19 in Australia: the first year. Deborah Lupton [Online]. Available at: https:// deborahalupton.medium.com/timeline-of-covid-19-inaustralia-1f7df6ca5f23; last accessed 28 February 2021.

Ryan, B., Martinez Ruiz, A., Rivera-Rodriguez, C., Curtis, M. and Cheung, G. (2021). Sociodemographic and clinical characteristics of 1350 patients with young onset dementia: a comparison with older patients. Alzheimer Disease and Associated Disorders. https://doi.org/ 10.1097/WAD.0000000000000435

Savla, J., Roberto, K. A., Blieszner, R., McCann, B. R., Hoyt, E. and Knight, A. L. (2020). Dementia caregiving during the "Stay-at-Home" phase of COVID-19 pandemic. The fournals of Gerontology: Series B, 76, e241-e245. https://doi.org/10.1093/geronb/gbaa129

Monica Cations, ${ }^{1}$ (i) Sally Day, ${ }^{1}$ Kate Laver, ${ }^{2}$ AdRIENNE WithaLL ${ }^{3}$ aND BRIAN DRAPER ${ }^{4}$ (D)

${ }^{1}$ College of Education, Social Work and Psychology, Flinders University, Bedford Park, South Australia, Australia

${ }^{2}$ College of Medicine and Public Health, Flinders University, Bedford Park, South Australia, Australia

${ }^{3}$ School of Public Health and Community Medicine, University New South Wales Sydney, Sydney, New South Wales, Australia

${ }^{4}$ School of Psychiatry, University New South Wales Sydney, Sydney, New South Wales, Australia

Correspondence should be addressed to: Monica Cations, College of Education, Psychology and Social Work, Flinders University, GPO Box 2100 ADELAIDE SA 5001, Phone: +61882013058. Email: monica .cations@flinders.edu.au. 